\title{
The GABAergic septohippocampal connection is impaired in a mouse model of tauopathy
}

\author{
Helena Soler a,b , Jonatan Dorca-Arévalo ${ }^{\mathrm{a}, \mathrm{b}}$, Marta González ${ }^{\mathrm{a}, \mathrm{b}}$, Sara Esmeralda Rubio ${ }^{\mathrm{a}, \mathrm{b}}$, \\ Jesús Ávila ${ }^{\mathrm{b}, \mathrm{c}}$, Eduardo Soriano a,b,d,e, Marta Pascual ${ }^{\mathrm{a}, \mathrm{b}, \mathrm{d}, *}$
}

a Department of Cell Biology, Parc Cientific de Barcelona and Institute of Neurosciences, University of Barcelona, Barcelona, Spain

${ }^{\mathrm{b}}$ Centro de Investigación Biomédica en Red sobre Enfermedades Neurodegenerativas (CIBERNED, ISCIII), Madrid, Spain

${ }^{\mathrm{c}}$ Centro de Biología Molecular Severo Ochoa (CSIC-UAM), Neurobiology Laboratory, Madrid, Spain

${ }^{\mathrm{d}}$ Institut de Recerca de l'Hospital Universitari de la Vall d'Hebron (VHIR), Barcelona, Spain

${ }^{\mathrm{e}}$ Institució Catalana de Recerca i Estudis Avançats Academia, Barcelona, Spain

\section{A R T I C L E I N F O}

\section{Article history:}

Received 25 May 2016

Received in revised form 5 September 2016 Accepted 8 September 2016

Available online 15 September 2016

\section{Keywords:}

Alzheimer's disease

Hippocampal interneurons

Parvalbumin-positive cells

VLW mice

Hyperphosphorylated Tau

\begin{abstract}
A B S T R A C T
Alzheimer's disease (AD), the most common cause of dementia nowadays, has been linked to alterations in the septohippocampal pathway (SHP), among other circuits in the brain. In fact, the GABAergic component of the SHP, which controls hippocampal rhythmic activity crucial for learning and memory, is altered in the J20 mouse model of AD-a model that mimics the amyloid pathology of this disease. However, AD is characterized by another pathophysiological hallmark: the hyperphosphorylation and aggregation of the microtubule-associated protein Tau. To evaluate whether tauopathies alter the GABAergic SHP, we analyzed transgenic mice expressing human mutated Tau (mutations G272V, P301L, and R406W, VLW transgenic strain). We show that pyramidal neurons, mossy cells, and some parvalbumin (PARV)-positive hippocampal interneurons in 2- and 8-month-old (mo) VLW mice accumulate phosphorylated forms of Tau (P-Tau). By tract-tracing studies of the GABAergic SHP, we describe early-onset deterioration of GABAergic septohippocampal (SH) innervation on PARV-positive interneurons in 2-mo VLW mice. In 8-mo animals, this alteration was more severe and affected mainly P-Tau-accumulating PARV-positive interneurons. No major loss of GABAergic SHP neurons or PARV-positive hippocampal interneurons was observed, thereby indicating that this decline is not caused by neuronal loss but by the reduced number and complexity of GABAergic SHP axon terminals. The decrease in GABAergic SHP described in this study, targeted onto the PARV-positive/P-Tau-accumulating inhibitory neurons in the hippocampus, establishes a cellular correlation with the dysfunctions in rhythmic neuronal activity and excitation levels in the hippocampus. These dysfunctions are associated with the VLW transgenic strain in particular and with AD human pathology in general. These data, together with our previous results in the J20 mouse model, indicate that the GABAergic SHP is impaired in response to both amyloid- $\beta$ and P-Tau accumulation. We propose that alterations in the GABAergic SHP, together with a dysfunction of P-Tau-accumulating PARVpositive neurons, contribute to the cognitive deficits and altered patterns of hippocampal activity present in tauopathies, including AD.
\end{abstract}

(C) 2016 Elsevier Inc. All rights reserved.

\section{Introduction}

Amyloid- $\beta$ deposits and Tau neurofibrillary tangles (NFTs) are the most typical neuropathological hallmarks of Alzheimer's disease (AD) (Bloom, 2014; Castellani et al., 2010; Selkoe, 1991). The cholinergic component of the basal forebrain, including the medial septum-diagonal band of Broca (MSDB) and the nucleus basalis magnocellularis, innervating the cerebral cortex and the hippocampus, undergoes progressive deterioration in $\mathrm{AD}$ and also during

\footnotetext{
* Corresponding author at: Department of Cell Biology, Av Diagonal 643, 08028 Barcelona. Spain. Tel.: 34-934021553.

E-mail address: marpascual@ub.edu (M. Pascual).
}

normal aging. Moreover, it is believed that reduced function of the cholinergic septohippocampal pathway (SHP) may underlie early impairment of hippocampus-based episodic memory (Whitehouse et al., 1982; Ypsilanti et al., 2008).

In addition to the cholinergic pathway, the SHP has a second important component, namely GABAergic neurons (Freund and Antal, 1988; Gulyas et al., 1990). This long-range inhibitory pathway terminates specifically on GABAergic hippocampal interneurons, which in turn regulate the activity of pyramidal neurons. It has been proposed that activation of GABAergic SHP neurons leads to the selective inhibition of inhibitory interneurons, thereby allowing the synchronous activation of 
large numbers of pyramidal neurons. Thus, the GABAergic SHP may provide correct levels of excitation, as well as regulate synchronous neuronal activities, including the theta and gamma rhythms, which are essential for memory and cognition (Bland et al., 2007; Buzsáki, 2005; Freund and Gulyas, 1997; Garner et al., 2005; Hangya et al., 2009; Kitchigina et al., 2013; Sotty et al., 2003; Toth et al., 1997). Recent studies have reported alterations also in the GABAergic component of the SHP (Loreth et al., 2012) associated with AD in a triple-transgenic mouse line (TauPS2APP). In this regard, a mouse model with a considerable

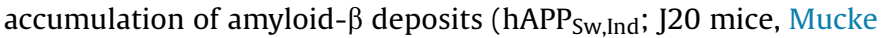
et al., 2000; Palop et al., 2003) shows a dramatic and early decrease in the GABAergic SHP. This decline is caused by the reduced number and complexity of GABAergic SHP axon terminals, which in turn correlates with changes in network activity and in the electrophysiology of the target hippocampus (Rubio et al., 2012; Vega-Flores et al., 2014).

Another feature observed in AD and in other neurodegenerative diseases is the hyperphosphorylation and aggregation of the microtubule-associated protein Tau. In this context phosphorylated forms of Tau (P-Tau) protein accumulates in the somatodendritic compartment that finally forms NFTs. NTFs are thought to cause synaptic and neuronal dysfunction and neuronal death. In addition, recent evidence indicates that soluble P-Tau protein is a key toxic species (Spires et al., 2006). Tauopathy leads to a loss of synapses and neurons, thus leading to cognitive and behavioral impairment (Ballatore et al., 2007; Frost et al., 2015).

The VLW mouse line overexpresses human Tau with 4 tubulinbinding repeats and 3 mutations (G272V, P301L, and R406W), associated with frontotemporal dementia and Parkinsonism linked to chromosome 17 (FTDP-17). Previous analysis of VLW mutant mice shows that cortical and hippocampal neurons accumulate prefibrillary Tau-aggregates in somata and dendrites-a phenomenon resembling the accumulation associated with $A D$ (Lim et al., 2001). VLW mice present severe memory impairment, including retention of episodic memory (Rodríguez-Navarro et al., 2008). In addition, hyperexcitability and epileptic activity have recently been described in this mouse model (García-Cabrero et al., 2013).

Here, we addressed whether the phosphorylation of pathological Tau leads to alterations in the GABAergic SHP connection that could cause cognitive deficits associated with tauopathies. Our data indicate that VLW mice accumulate P-Tau in pyramidal neurons and in PARV-positive interneurons in the hippocampus. VLW mutant mice show a decrease in GABAergic SHP innervation, and this reduction is not caused by neuronal loss but by a reduced number and complexity of GABAergic SHP synaptic contacts.

\section{Materials and methods}

\subsection{Animals}

For the histological procedures, we used wild-type male mice (C57BL/6J strain; 2 to 3 and 8 to 9-month-old [mo]; $\mathrm{n}=4-6$ per group) and homozygous transgenic male mice with the same genetic background that overexpress human Tau with 4 tubulinbinding repeats and 3 mutations (G272V, P301L, and R406W) associated with FTDP-17 (VLW line; 2 to 3 and 8 to $9-\mathrm{mo} ; \mathrm{n}=5-6$ per group). All animals were kept on a 12 hours light/dark schedule with access to food and water ad libitum. All animal experiments were performed in accordance with the European Community Council Directive and the National Institute of Health guidelines for the care and use of laboratory animals. Experiments were also approved by the local ethical committees.

\subsection{Detection of septohippocampal fibers}

Animals were deeply anesthetized (mixture 10/1 Ketolar [ParkeDavis]/Rompun [Bayer], $0.003 \mathrm{~mL} / \mathrm{g}$ ) and stereotaxically injected with an anterograde tracer (10\% biotinylated dextran-amine [BDA] $10,000 \mathrm{MW}$, Molecular Probes) in the MSDB complex. Each animal received midline injections of the tracer into the MSDB complex at 1 anteroposterior (AP) level and at 2 dorsoventral (DV) injection points by iontophoresis (7- $\mu \mathrm{A}$ positive direct current, 7 seconds on-off cycle). Stereotaxic coordinates were (from Bregma): $\mathrm{AP}+0.7$, and $\mathrm{DV}-3.0$ and -3.7 . This protocol results in intense BDA labeling in the MSDB complex area, which contains the highest proportion of GABAergic SH neurons (Pascual et al., 2004). Five or 6 days later, the animals were deeply anesthetized and perfused with $4 \%$ paraformaldehyde in $0.12-\mathrm{M}$ phosphate buffer. The brains were frozen and $30-\mu \mathrm{m}$ sections were cut. Coronal sections were stored in a cryoprotectant solution (30\% glycerin, 30\% ethylene glycol, $40 \%$ 0.1 -M phosphate buffer) at $-20{ }^{\circ} \mathrm{C}$ until use. To visualize BDA, after blocking, the sections were incubated overnight at $4{ }^{\circ} \mathrm{C}$ with the ABC complex (Vectastain ABC Kit; Vector Laboratories, Burlingame, CA, USA) diluted $1 / 100$. Peroxidase activity was developed with diaminobenzidine intensified with nickel ammonium sulfate and cobalt chloride (DAB/Ni-Co) and $\mathrm{H}_{2} \mathrm{O}_{2}$. Thereafter, sections were mounted onto gelatinized slides, Nissl-stained, and coverslipped with Eukitt.

\subsection{Immunodetection}

Some hippocampal sections from each of the iontophoretically injected animals were processed for the double immunodetection of BDA and several interneuronal markers (Matyas et al., 2004; Pascual et al., 2004; Rocamora et al., 1996). After blocking, freefloating sections of the tissue were incubated overnight at $4{ }^{\circ} \mathrm{C}$ with the $\mathrm{ABC}$ complex (Vectastain $\mathrm{ABC}$ Kit; Vector Laboratories) diluted $1 / 100$ simultaneously with well-characterized rabbit polyclonal antibody (Swant Antibodies, Switzerland) against parvalbumin (PARV, 1/3000) or glutamic acid decarboxylase 65/67 (GAD65/ 67, Chemicon International, Temecula, CA, USA) diluted 1/1000. BDA was revealed using $\mathrm{DAB} / \mathrm{Ni}-\mathrm{Co}$, yielding a black end product in $\mathrm{SH}$ fibers. Primary antibodies were then visualized by sequential incubation with biotinylated secondary antibodies and the $A B C$ complex (2 hours each, Vector Laboratories). The peroxidase reaction was developed with DAB to produce a brown end product. The sections were mounted onto gelatinized slides, dehydrated, and coverslipped with Eukitt.

To detect the accumulation of P-Tau, tissue sections from VLW mice were blocked and incubated overnight with AT-180 mouse anti-phosphothreonine 231 in Tau (1/300) (Goedert et al., 1994). Primary antibody visualization was performed by sequential incubation with anti-mouse biotinylated secondary antibodies and $A B C$ complex (Vector Laboratories). Peroxidase activity was developed with $\mathrm{DAB} / \mathrm{Ni}$-Co to intensify the signal. Some sections of iontophoretically injected VLW animals were processed for double detection of BDA injected in the MSDB (DAB/Ni-Co, black signal) and P-Tau immunodetection (DAB alone, brown signal).

For double immunofluorescent detection of P-Tau and PARV, calretinin (CALR), calbindin (CALB), or somatostatin (SOM), the sections were incubated overnight simultaneously with rabbit anti-PARV (1/3000), anti-CALR (1/2000), anti-CALB (1/3000, Swant Antibodies, Switzerland), or anti-SOM (1/1000, Chemicon International, Temecula, CA, USA) antibodies and AT-180 mouse anti-PThr231 (1/300). Some sections were stained with rabbit anti-PARV antibody $(1 / 3000)$ combined with mouse antibodies AT-8 (1/500) and 12E8 (1/500) to recognize Tau protein phosphorylated in Ser202/Thr205 and Ser262/Ser356, respectively. 
In all double immunodetections, the sections were incubated with Alexa Fluor 568 goat anti-rabbit IgG and Alexa Fluor 488 goat antimouse IgG (Invitrogen, Carlsbad, CA, USA) for 2 hours. They were then mounted onto slides, coverslipped with Mowiol 4-88 (Merck, Darmstadt, Germany), and viewed under a confocal microscope.

Sections corresponding to the MS were used for fluorescent immunodetection of PARV. After blocking, tissue was incubated overnight with anti-PARV antibody and then incubated with Alexa Fluor 488 donkey anti-rabbit IgG (Invitrogen). The sections were mounted and coverslipped with Mowiol 4-88.

\subsection{Analysis of the histological sections}

Microscopic observations were focused on sections corresponding to the MS and to dorsal (sections between 1.60 and $2.30 \mathrm{~mm}$ posterior to Bregma) and ventral (sections 2.90 and $3.40 \mathrm{~mm}$ posterior to Bregma) hippocampal levels, following the atlas reported by Paxinos and Franklin (Paxinos and Franklin, 2001). To estimate the density of GABAergic SH neurons, PARV-immunopositive cells in the MSDB complex in serial sections of brains (8-mo WT and VLW mice, $\mathrm{n}=4-6$ animals/genotype; 3-5 sections/animal) were counted manually under a fluorescent optical microscope (Nikon E600; Nikon Corp, Kawasaki, Japan), and the results were expressed as number of PARV-positive cells in the MSDB area per section.

To estimate the density of hippocampal interneurons and the percentage of these cells contacted by GABAergic SH fibers, the density of interneurons containing PARV or P-Tau, as well as the percentage of these interneurons receiving the BDA-positive pericellular baskets, was calculated in the distinct regions of the hippocampal area (DG, CA3, and CA1) of each section (4-6 animals/ genotype and age, $4-8$ sections/animal). The area comprising the hippocampal regions of each section was quantified using ImageJ program. The density of hippocampal interneurons was defined as the density of interneurons per square millimeter. A similar procedure was performed for GAD65/67-immunopositive cells. However, in this case, due to the large number of GAD65/67-positive cells, we selected several sample areas for each section. The selected samples (125- $\mu$ m-wide stripes) contained all hippocampal layers (perpendicularly from the ventricle to the pial surface), and each section included 1 stripe in the DG, 2 in the CA3, and 3 in the CA1. For GAD65/67 quantification, 4-6 animals/genotype and age were used, and 4-8 sections/animal were analyzed. Data were represented as above (density of interneurons per square millimeter and percentage of GAD67/65-positive cells contacted by GABAergic SH fibers).

To assess the complexity of the GABAergic SH contacts, synaptic boutons around the somata of hippocampal interneurons were counted under a conventional microscope for GAD65/67-positive, for P-Tau, and for PARV-positive interneuron subpopulations, using the procedure previously described.

To quantify the intensity of the AT-180 immunodetection signal, optical density was obtained by scanning (SilverFast) and analyzed by Fiji software. Four VLW mice/age (2- and 8-mo) and 5-7 sections/animal processed simultaneously were included in the analysis.

\subsection{Statistical analysis of histological data}

For the statistical analysis, we estimated the densities of GABAergic SH (PARV-immunopositive) cells per section for each mouse. For each hippocampal interneuronal population studied (PARV-, GAD65/67, or P-Tau-immunopositive neurons), the density of interneurons per square millimeter, percentage of contacted interneurons, and number of boutons per single basket were estimated for each hippocampal area or for total hippocampal region.
In all statistical analyses, the number of animals was considered as replicates $(\mathrm{n}=4-6$ animals/genotype and age, $4-8$ sections/animal were used).

Histological data were processed for statistical analysis with StatGraphics Plus 5.1 (Statistical Graphics, Rockville, MD, USA). Two-sample Student $t$ test (2-tailed) or Mann-Whitney W test (2-tailed) was used (when the samples fitted a normal distribution or not, respectively) to examine differences between the experimental groups. The significance was set at $p<0.05$ for the 2 -tailed tests. Statistical information is reported throughout the text in the format: statistic (degrees of freedom) $=$ value, $p=$ value.

\section{Results}

\subsection{Distribution of P-Tau in VLW mice}

To characterize the distribution of P-Tau, we performed immunodetection using AT-180 antibody on sections from 2- and 8-mo VLW mice. The AT-180 antibody specifically recognizes Tau protein phosphorylated in Threonine 231. As previously described (Lim et al., 2001), in adult animals (8-mo), neurons in the pyramidal layer of the CA1 accumulated high levels of Thr231P-Tau in the soma and proximal dendrites (Fig. 1A). In addition, these animals also accumulated AT-180-positive P-Tau in mossy cells in the dentate gyrus (DG, Fig. 1G), in some pyramidal neurons in the CA3 region (Fig. 1A), and in some sparsely distributed cells in all hippocampal regions (Fig. 1D, arrows).

The AT-180 signal in the mossy cells was weaker in 2-mo mice than that in older mice (DG, Fig. 1B). In addition, CA1-CA3 pyramidal neurons and some neurons scattered in distinct hippocampal strata and regions presented P-Tau accumulation since 2 months (Fig. 1E, arrows). Quantification of the intensity of the AT180-positive immunostaining in the CA3 and CA1 pyramidal layer and in the hilus of the DG revealed no differences regarding the level of AT-180-positive P-Tau accumulation in 2-mo VLW mice, compared to that of 8-mo VLW mice (CA3: $156382.05 \pm 2827.4$ and $157629.2 \pm 1805.5$ arbitrary units, respectively, $\mathrm{t}[6]=0.38, p=0.70$, Student $t$ test; CA1: $158063.7 \pm 637.3$ and $158668.4 \pm 1942.6$ arbitrary units, respectively, $\mathrm{t}[6]=0.29, p=0.77$, Student $t$ test; and DG: $155344.5 \pm 2484.4$ and $159484.6 \pm 2140.3$ arbitrary units, respectively, $\mathrm{t}[6]=1.2, p=0.24)$.

Our recent data (Rubio et al., 2012) showed an important decrease in SH innervation in a mouse model of AD with amyloid- $\beta$ accumulation; because we were interested in analyzing SH innervation in VLW mice, we first tested whether SH neurons accumulated P-Tau in this mouse model. We found that no cells expressing AT-180-positive P-Tau were present in the MSBD region of 2- or 8-mo animals (Fig. 1C). In addition, no accumulation was observed in control mice in any region analyzed (Fig. 1F). Thus, our results show that in VLW mice P-Tau accumulate in CA1 and CA3 pyramidal neurons, in the mossy cells, and in neurons scattered throughout hippocampal layers.

\subsection{PARV-positive hippocampal interneurons accumulate P-Tau in VLW mice}

A more detailed analysis of scattered AT-180-positive cells in 8-mo mice revealed that they were located mainly in the strata oriens and radiatum close to the pyramidal layer (Fig. 1D and E), and also near the granule cell layer. The distribution and morphology of these AT-180-positive cells seemed to correspond to basket and axoaxonic hippocampal interneurons containing PARV (Freund and Buzsaki, 1996; Matyas et al., 2004). To ascertain whether the PARVpositive neurons of VLW mice present P-Tau, we performed double immunofluorescent detection against PARV and AT-180. Our results 

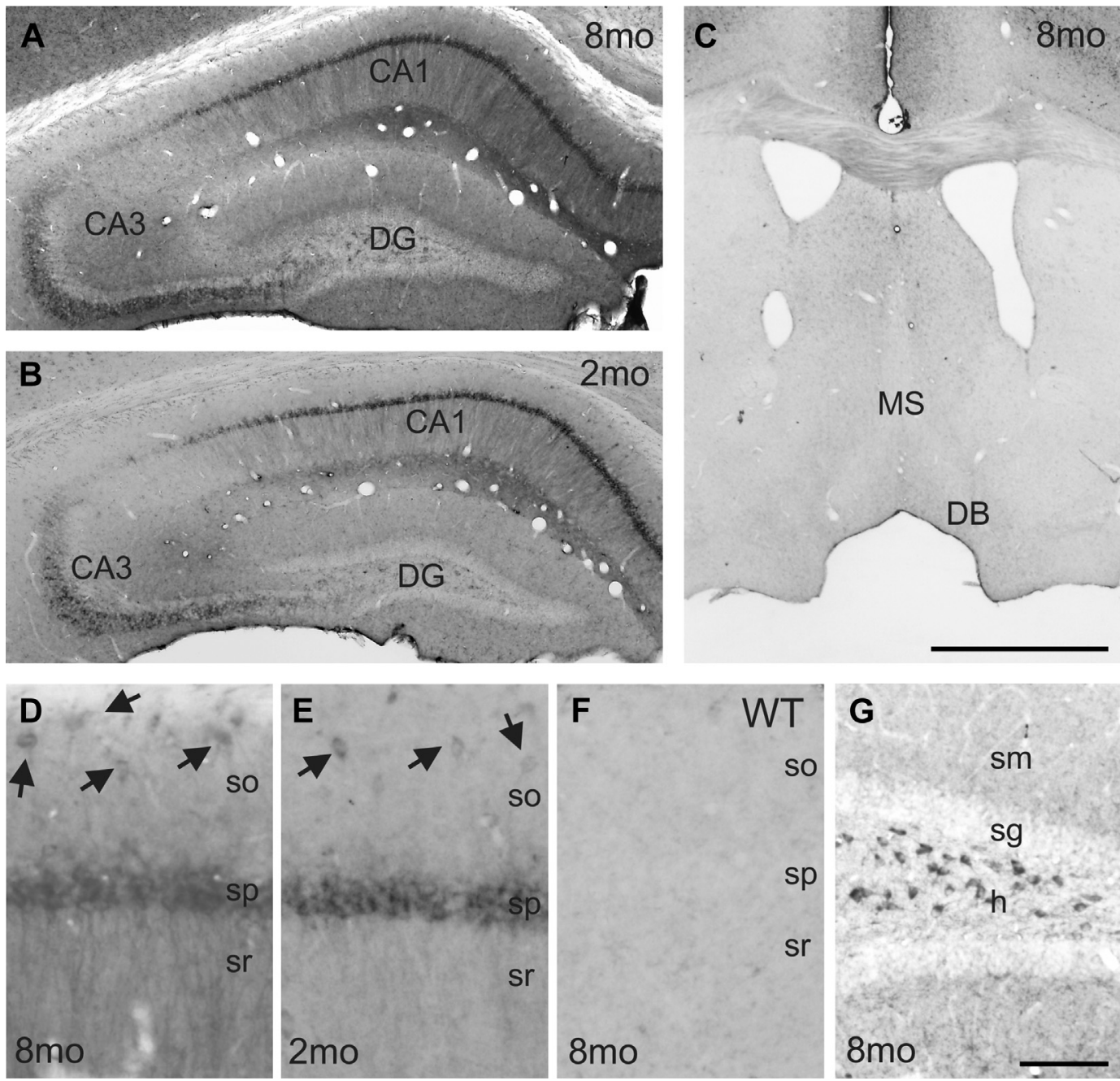

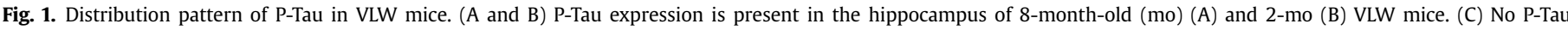

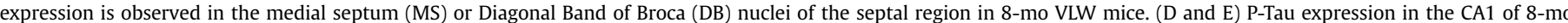

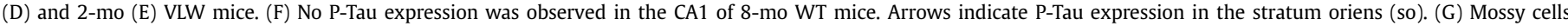

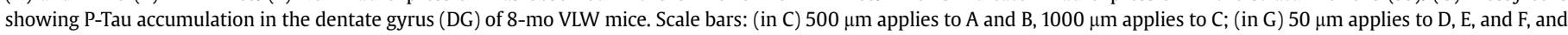

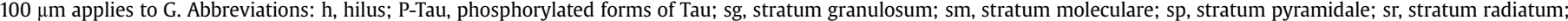
WT, wild-type mouse.

showed that some, but not all, PARV-positive cells in the CA1, CA3, and DG accumulated AT-180-positive P-Tau forms in soma and proximal dendrites of 8-mo animals (Fig. 2A-F). Double-positive cells were also observed in the CA1, CA3, and DG of 2-mo animals (Fig. 2J-L). To examine whether P-Tau also accumulates in other hippocampal populations, we performed double immunodetection against P-Tau and CALR, SOM, and CB, markers for specific populations of hippocampal interneurons (Freund and Buzsaki, 1996; Gulyas et al., 1996; Matyas et al., 2004). No colocalization of P-Tau and CALR was observed in any region analyzed (Fig. 2G-I). Neither was colocalization detected between P-Tau and SOM or CB (data not shown). To analyze whether PARV-positive cells accumulate Tau protein phosphorylated exclusively in Thr231 or also Tau phosphorylated in other residues, we performed double immunodetections combining PARV and AT-8 or 12E8, which recognize Ser202/Thr205 and Ser262/Ser356, respectively. Although an intense positive signal was present in the pyramidal cell layer (Supplementary Fig. 1A, B), no AT-8- or 12E8-positive signal was found in PARV-positive cells in VLW mice (Supplementary Fig. 1C-H). Thus, our data indicated that PARV-positive hippocampal neurons in this mouse model specifically accumulate Tau phosphorylated in Thr231.

\subsection{No major loss of GABAergic hippocampal interneurons in VLW} mice

Our results showed that hippocampal interneurons accumulate P-Tau forms in VLW mice. Such accumulation has been described to be an initial feature of neurodegeneration (Ballatore et al., 2007; Frost et al., 2015); consequently, we studied whether VLW mice present GABAergic neuronal death and, accordingly, an alteration in the number of hippocampal interneurons. With this aim, we performed GAD65/67 immunodetections on 2- and 8-mo VLW and control mice to stain all GABAergic cells in the hippocampus (Fig. 3A and B). First, we analyzed the density of hippocampal interneurons during the maturation, comparing the number of GAD- and PARV-positive cells in 2- and 8-mo VLW and WT mice. Our data showed that the density of GAD-positive (2-mo: $183.0 \pm 15.6$ and 8-mo: $209.2 \pm 13.72$ GAD-positive cells $/ \mathrm{mm}^{2}$ ) and PARV-positive (2-mo: $51.49 \pm 5.17$ and 8-mo: $52.15 \pm 2.19$ PARV-positive cells $/ \mathrm{mm}^{2}$ ) cells remained constant in the former and also in the 2 stages of WT mice (2-mo: $186.19 \pm$ 13.08 and 8-mo: $184.55 \pm 7.22$ GAD-positive cells $/ \mathrm{mm}^{2}$ and 2-mo: $48.50 \pm 8.09$ and 8-mo: $48.05 \pm 1.83$ PARV-positive 


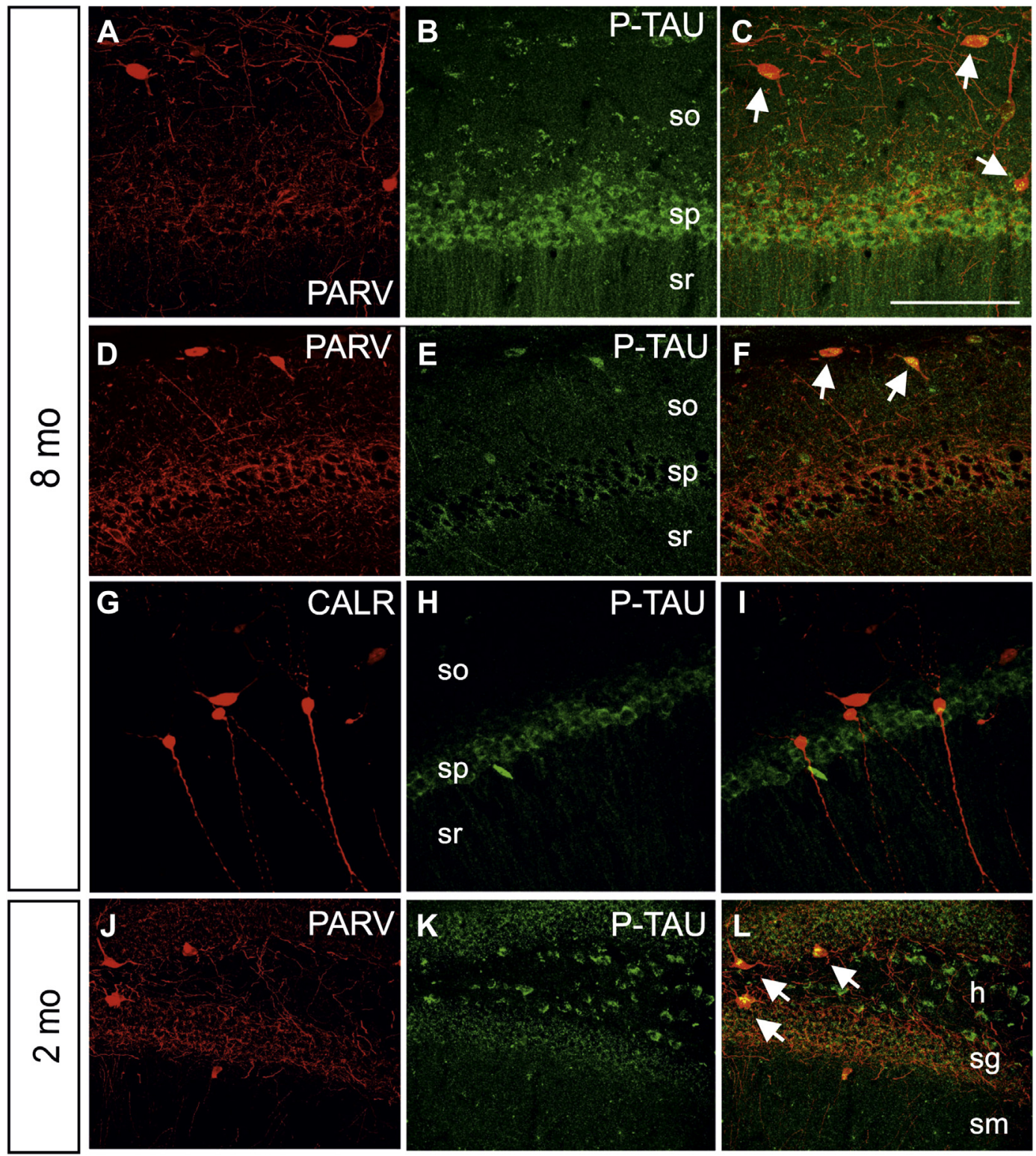

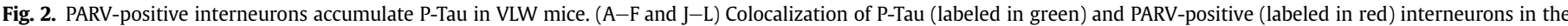

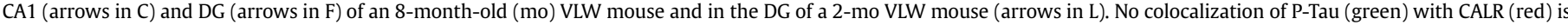

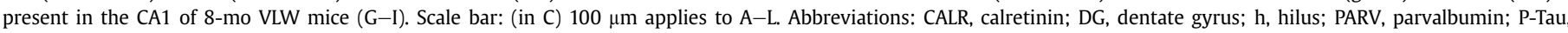
phosphorylated forms of Tau; sg, stratum granulosum; sm, stratum moleculare; so, stratum oriens; sp, stratum pyramidale; sr, stratum radiatum.

cells $/ \mathrm{mm}^{2}$ ), thereby indicating no increase or decrease in the number of hippocampal interneurons in WT or VLW mice between 2- and 8-mo.

In addition, no reduction in the density of GAD65/67-positive neurons in the hippocampus of VLW mice compared with WT animals was detected in 2- or 8 -mo mice $(\mathrm{t}[6]=0.15, p=0.88$ and $\mathrm{t}$ $[9]=1.49, p=0.16$, respectively, Student $t$ test) (Fig. 3C). Because PARV-positive cells of VLW mice accumulated P-Tau, we also specifically analyzed the population of PARV-positive interneurons (Fig. 3D and E). Our data indicated no alterations in the density of PARV-positive cells in 2- or 8-mo VLW mice $(\mathrm{t}[6]=0.38, p=0.71$ and $\mathrm{t}[8]=0.25, p=0.80$, respectively, Student $t$ test; Fig. $3 \mathrm{~F}$ ), thus excluding the occurrence of hippocampal interneuron degeneration in these animals.

\subsection{Reduction of GABAergic SH innervation on GAD-positive interneurons accumulating P-Tau}

To trace the GABAergic SHP in the VLW mouse model, we performed iontophoretic injections of BDA in the MS, following a protocol which virtually fills the MSDB complex with tracer (Pascual et al., 2004). As shown previously, SHP axons innervated all layers of the hippocampus and DG, and 2 types of fiber were clearly distinguished, namely thin axons with numerous "en passant" boutons, corresponding to cholinergic fibers, and thick GABAergic axons that established complex basket-like nets with large boutons around the perisomatic region of hippocampal interneurons (Freund and Antal, 1988; Pascual et al., 2005; Rocamora et al., 1996; Rubio et al., 2012). 

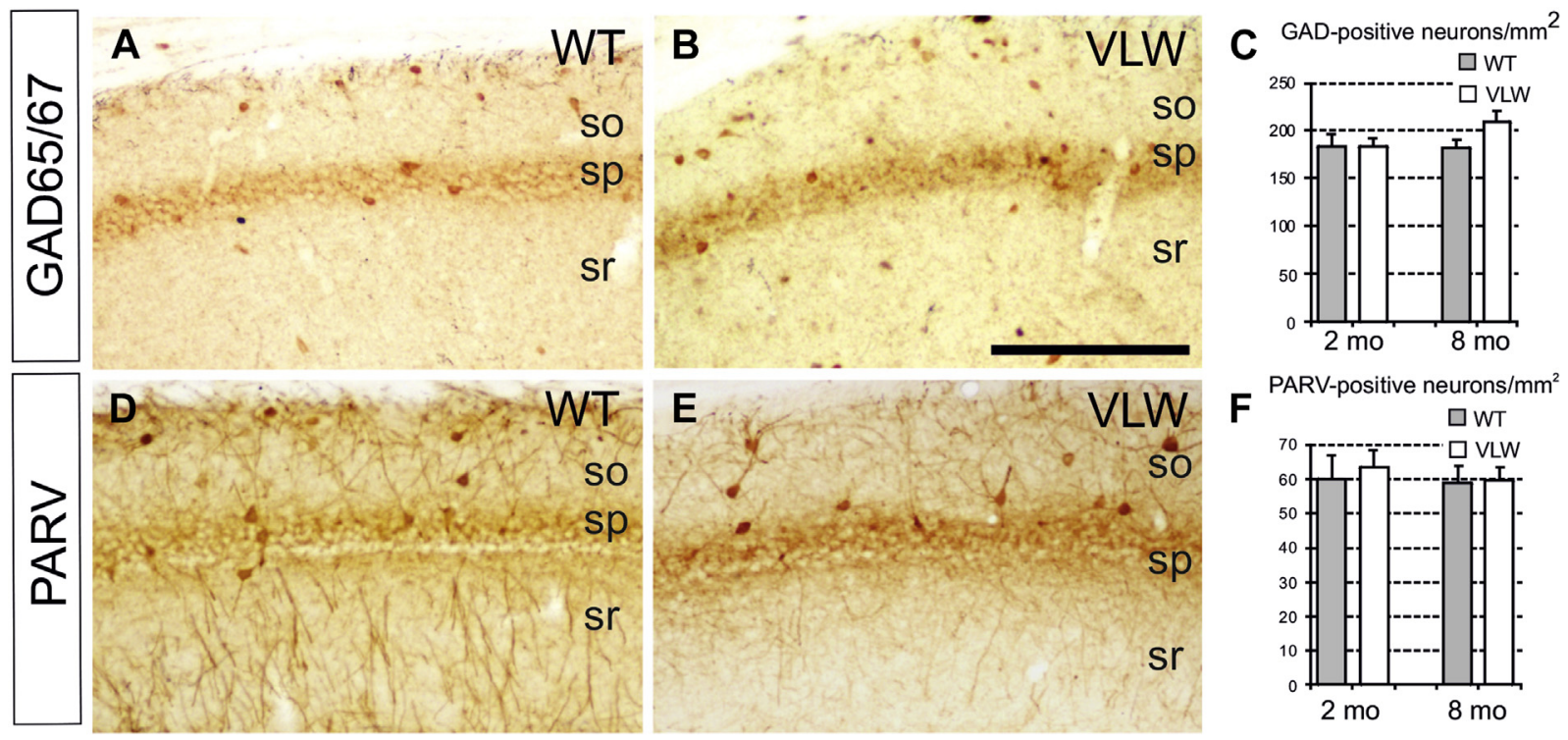

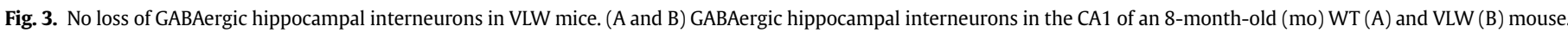

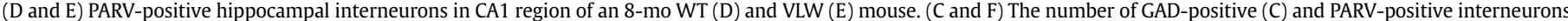

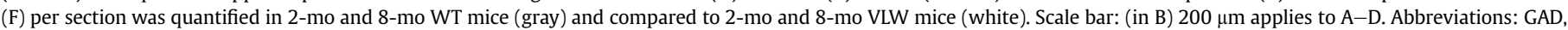
glutamic acid decarboxylase; HIPP, total hippocampus; PARV, parvalbumin; so, stratum oriens; sp, stratum pyramidale; sr, stratum radiatum; WT, wild-type mouse.

Sections from 2- and 8-mo VLW mice and the corresponding control WT animals were simultaneously stained for BDA and GAD65/67, the later as a marker for all GABAergic hippocampal interneurons. The pattern of GABAergic SH innervation in VLW mice was indistinguishable from that observed in the WT group (Fig. 4A and B). No significant differences between 2-mo VLW and control mice were observed in the percentages of contacted GAD65/67-positive hippocampal interneurons (Fig. 4C-E), neither in the complexity of GABAergic SH contacts (Fig. 4C, D, and F).

However, although no statistical differences were observed at 8-mo, there was a clear downward trend in the percentages of GAD65/67-positive hippocampal interneurons contacted by the GABAergic SH fibers between VLW and control mice (Fig. $4 \mathrm{G}, \mathrm{H}$, and J). Neither were differences in the complexity of GABAergic $\mathrm{SH}$ contacts on GAD-positive hippocampal interneurons (Fig. 4K, $\mathrm{L}$, and $\mathrm{N}$ ). To address whether the downward trend in the GABAergic SH innervation observed at 8 months specifically affects P-Tau-accumulating interneurons, we costained sections from 8-mo VLW mice with P-Tau antibodies and BDA (Fig. 4I and M). Although the percentage of P-Tau-positive cells receiving GABAergic SH innervation was similar to the overall population of GAD-positive cells in VLW mice (Fig. 4H-J), the complexity of the synaptic contacts (boutons/cell) was reduced by $40 \%$ (t $[6]=$ 7.36, $p$-value $=0.00015$, Student $t$ test) (Fig. $4 \mathrm{~L}-\mathrm{N}$ ). Our data support the notion that GABAergic SHP innervation is decreased selectively in hippocampal interneurons accumulating P-Tau in mice carrying the VLW mutations.

\subsection{GABAergic SH innervation is specifically diminished on PARV-positive cells in VLW transgenic mice}

One of the main targets of GABAergic SH fibers is the PARVpositive population of interneurons. These basket and axo-axonic PARV-containing cells are essential for correct hippocampal function. In this regard, they are responsible for establishing hippocampal synchronous rhythms, which are crucial for learning and memory (Cardin et al., 2009; Freund and Buzsaki, 1996; Pike et al., 2000).
Since VLW mice have cognitive deficits (García-Cabrero et al., 2013; Rodríguez-Navarro et al., 2008) and the above results showed a considerable accumulation of P-Tau specifically in basket and axo-axonic PARV-positive interneurons, we next combined the detection of BDA with PARV labeling to study whether P-Tau accumulation in PARV-positive cells alters their GABAergic $\mathrm{SH}$ innervation specifically in these hippocampal interneurons. As shown previously, our data indicated an early accumulation of P-Tau forms in PARV-positive cells, so we next analyzed 2-mo VLW mice. A reduced percentage of PARV-positive cells contacted by GABAergic SH fibers was visible only in the DG of VLW mice $(t$ $[6]=4.28 ; p$-value $=0.032$, Student $t$ test; Fig. $5 \mathrm{G}$ ). The number of $\mathrm{SH}$ boutons per PARV-positive neuron was also diminished in the CA3 in these animals $(\mathrm{t}[6]=2.49, p$-value $=0.02$, Student $t$ test; Fig. 5C, E, and $\mathrm{H}$ ).

In 8-mo old mice, the pattern of $\mathrm{SH}$ innervation and the distribution of PARV-positive interneurons were indistinguishable between WT and VLW mice (Fig. 5A and B). A considerable decrease in the percentage of contacted PARV-positive cells $(\mathrm{t}[8]=2.53$, $p$-values $=0.016$, Student $t$ test ) and in the complexity of GABAergic SH contacts was observed when considering all hippocampal regions of 8-mo VLW mice, compared to control mice and $(\mathrm{t}[8]=2.31$, $p$-value $=0.02$, Student $t$ test; Hipp, Fig. 5I and J, respectively). Although there were fewer PARV-positive cells innervated by GABAergic SHP axons in all hippocampal regions, the most severe effect was present in the DG $(\mathrm{t}[8]=4.28, p$-values $=0.0002$, Student $t$ test) and CA1 $(\mathrm{t}[8]=3.14, p=0.003$, respectively, Student $t$ test; Fig. 5I). The reduction in the number of boutons per PARVpositive cell affected mainly the CA1 and CA3 $(\mathrm{t}[8]=2.75$ and 2.62 , respectively, $p$-value $=0.01$, Student $t$ test; Fig. $5 \mathrm{~J}$ ).

Next, we analyzed the progression of GABAergic SH innervation during maturation, comparing GABAergic connection in 2- and 8-mo WT and VLW mice. As previously described (Rubio et al., 2012), no significant changes were observed in the percentage and complexity of GABAergic SH contacts on PARV-positive cells in any hippocampal region, except in CA1 (Supplementary Fig. 2A and $\mathrm{B}$ ), when comparing 2- and 8-mo WT mice. The percentage of PARV-positive neurons innervated by GABAergic SH fibers 

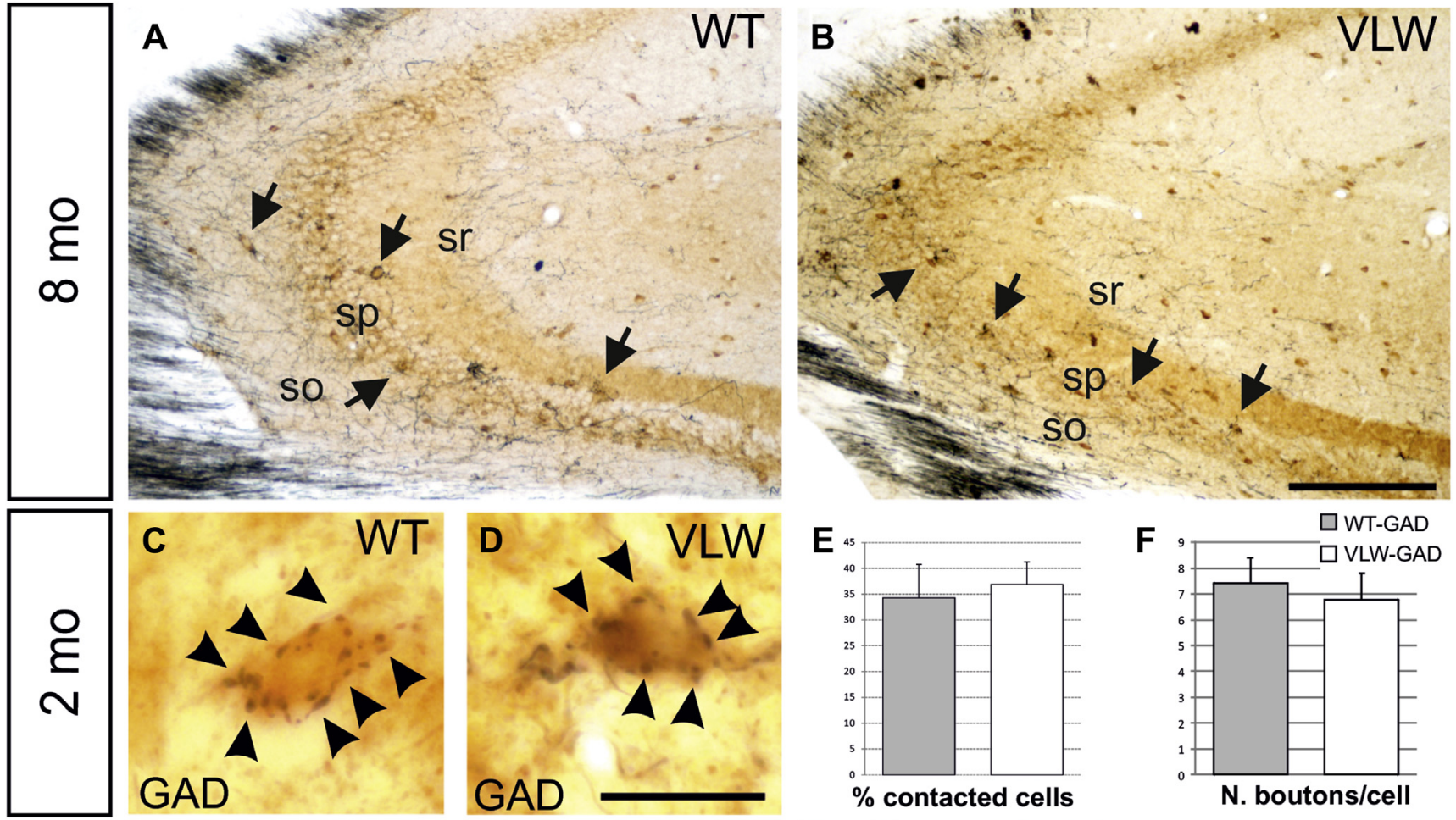

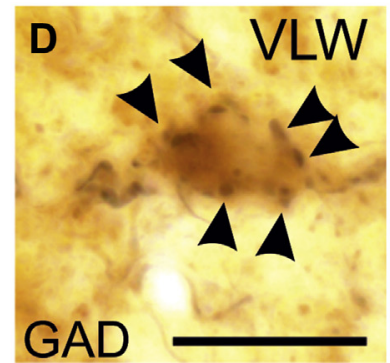

E
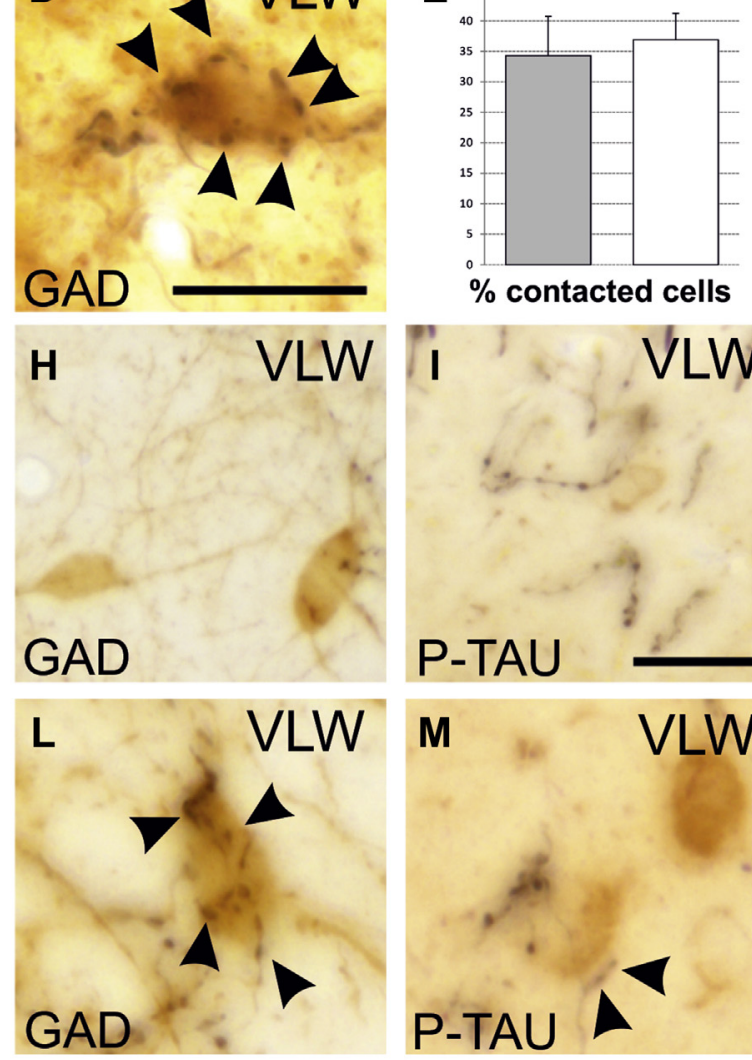
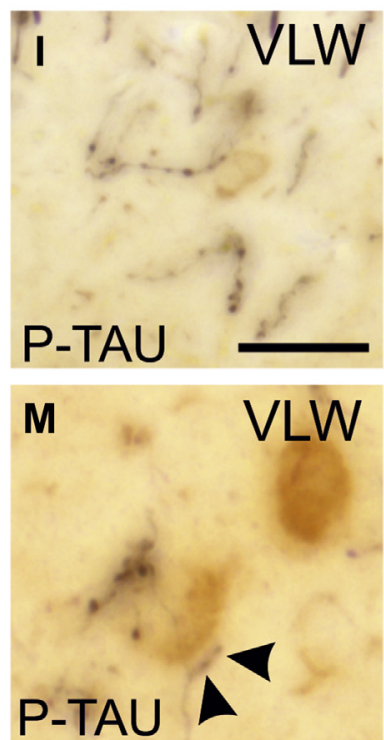

$\mathbf{F}$

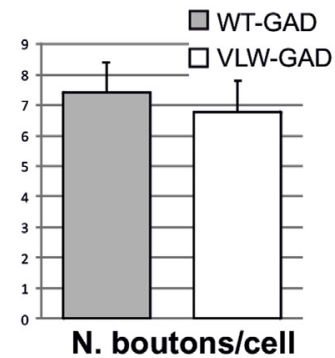

N. boutons/cell
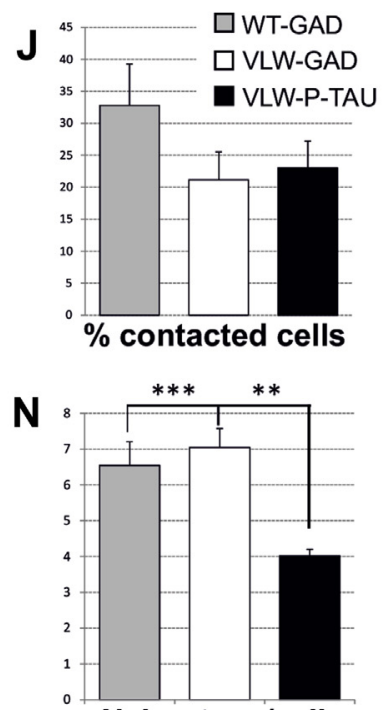

N. boutons/cell

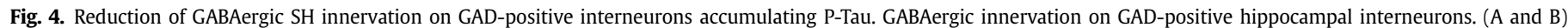

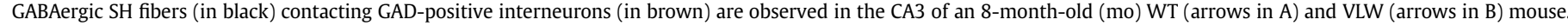

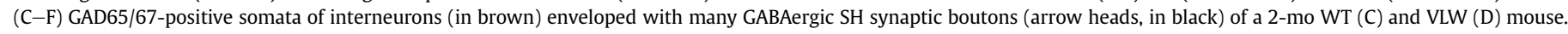

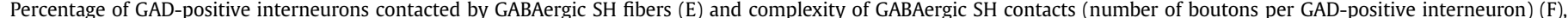

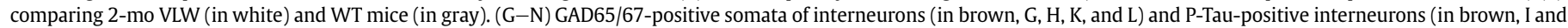

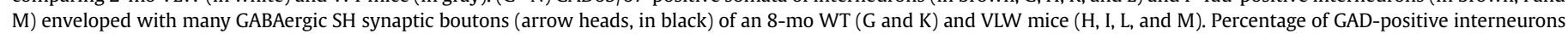

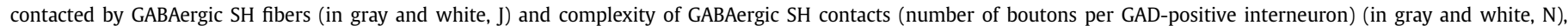

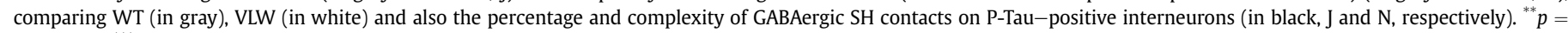

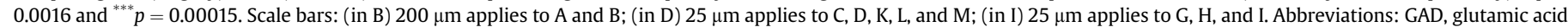
decarboxylase; P-Tau, phosphorylated forms of Tau; SH, septohippocampal; so, stratum oriens; sp, stratum pyramidale; sr, stratum radiatum; WT, wild-type mouse.

was significantly decreased in the CA1 of 8-mo WT mice $(\mathrm{t}[8]=$ 2.47, $p=0.02$, Student $t$ test). Subsequently, we analyzed VLW mice. Although the complexity of GABAergic SH contacts on PARV-positive cells remained constant in 2- and 8-mo VLW mice (Supplementary Fig. 2D), a considerable decrease in the percentage of innervated PARV-positive neurons was observed
(Supplementary Fig. 2C). Our data showed a significant diminution in the percentage of contacted PARV-positive neurons in the DG, CA1, and the total hippocampus $(\mathrm{t}[8]=2.64, p=0.013 ; \mathrm{t}[8]=0.29$, $p=0.006 ; \mathrm{t}[8]=2.02, p=0.046$, respectively, Student $t$ test). These data indicate an accelerated decrease in GABAergic SH innervation in VLW mice compared with WT mice. 

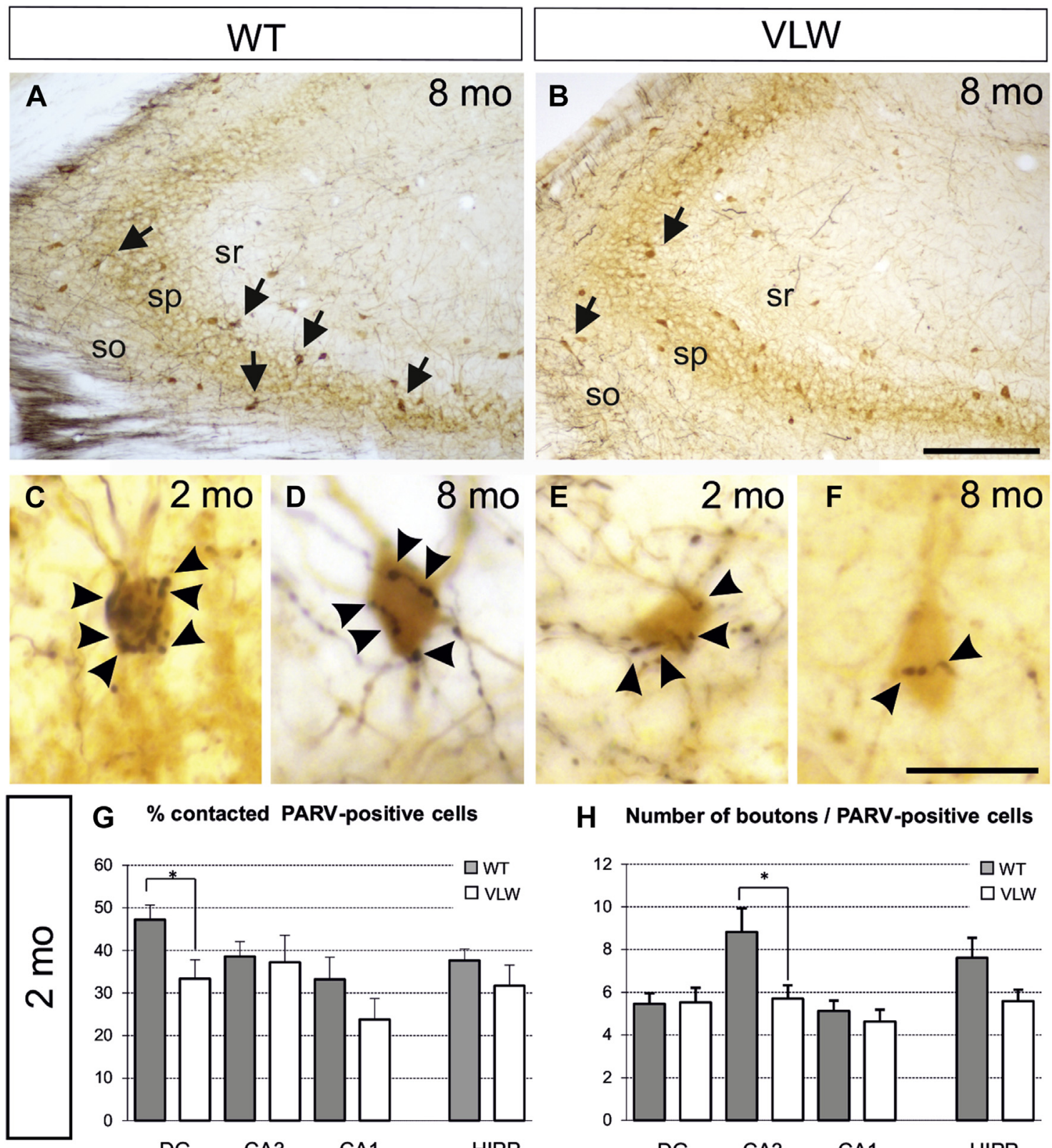

G \% contacted PARV-positive cells

H Number of boutons / PARV-positive cells
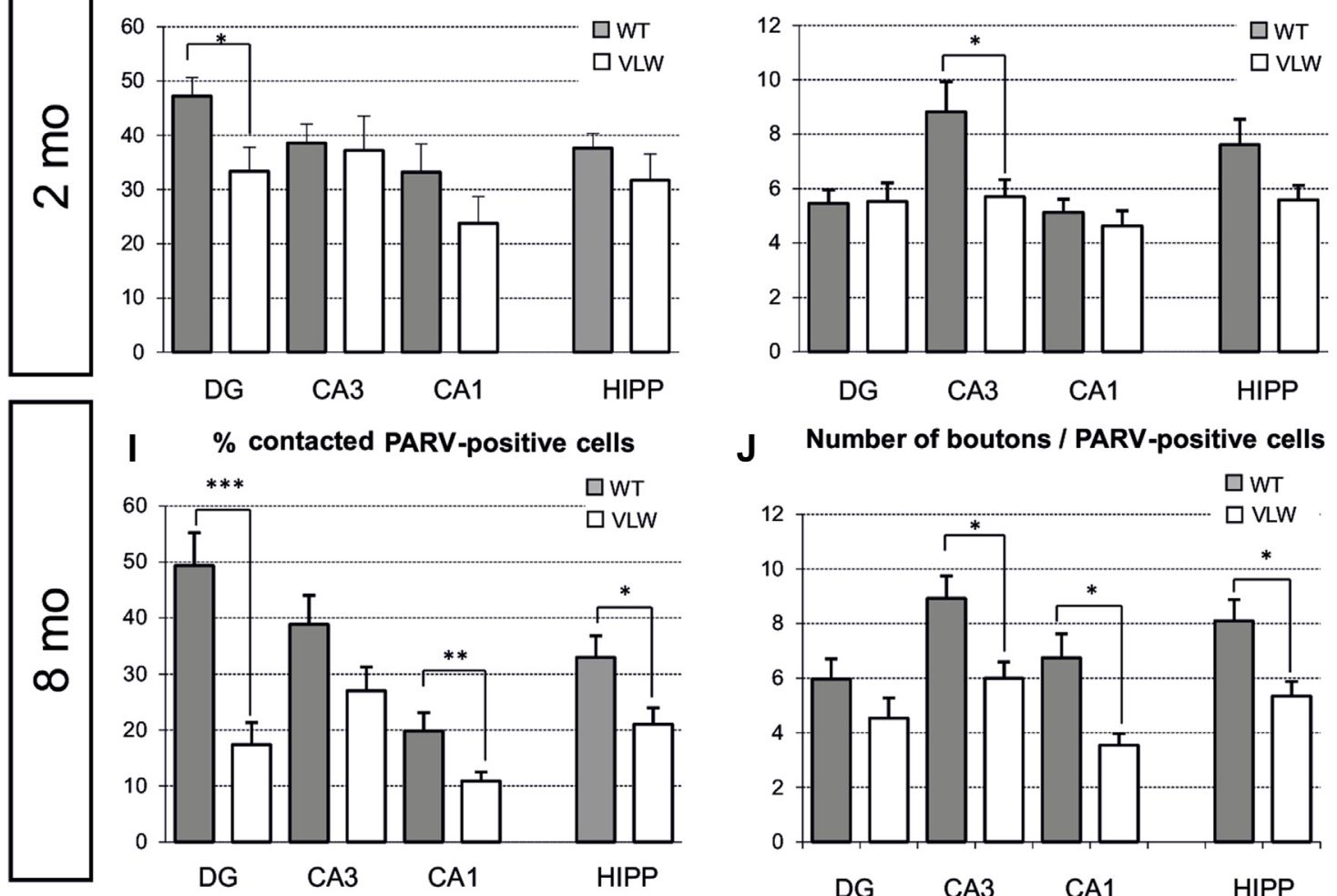

\section{J Number of boutons / PARV-positive cells}

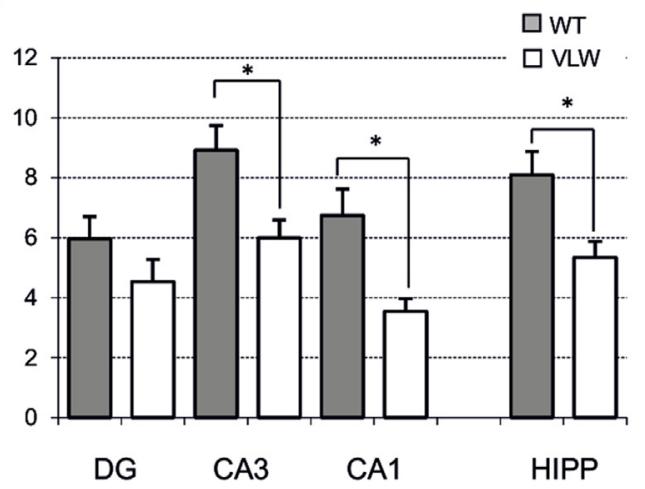

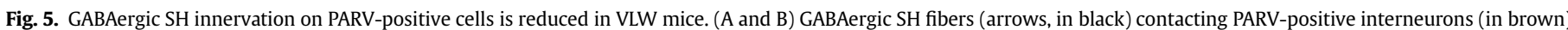

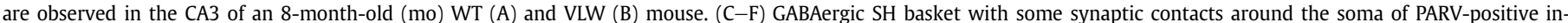

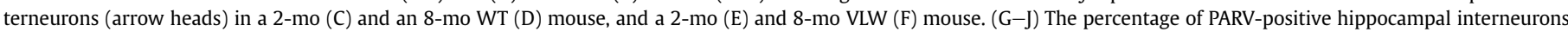

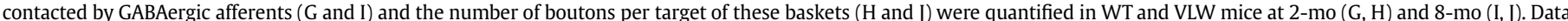

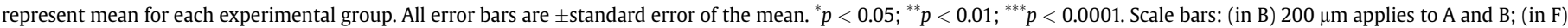

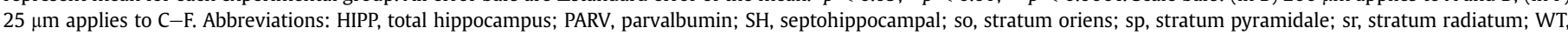
wild-type mouse. 
We thus conclude that GABAergic SHP innervation is reduced early and specifically on PARV-positive interneurons in VLW mice accumulating P-Tau.

\subsection{No major loss of GABAergic SH neurons in the MSDB}

To explore whether the decrease of GABAergic SH innervation in VLW mice is related to neuronal loss in the MSDB complex, we counted GABAergic PARV-positive SH neurons (Freund, 1989) in the septum. Statistical analyses indicated that the number of GABAergic SH neurons remained constant in 8-mo VLW mice (average $124.9 \pm$ 14.21 cells/section) compared to WT age-matched controls (121.69 \pm 5.6 cells/section; $\mathrm{U}[8]=0.229, p$-value $=0.82$, Mann-Whitney test; Fig. $6 \mathrm{~A}$ and $\mathrm{B}$ ). These data indicate that the reduction in GABAergic SH innervation in VLW mice is not related to neuronal loss in the MSDB but rather reflects decreased axonal and perisomatic basket complexity.

\section{Discussion}

The neuropathological hallmarks of $A D$ are amyloid- $\beta$ deposits and the aggregation of P-Tau protein, accompanied by a progressive deterioration of the cholinergic and GABAergic component of the basal forebrain system (Bloom, 2014; Castellani et al., 2010; Rubio et al., 2012; Ypsilanti et al., 2008). Electrophysiological and biochemical data obtained in transgenic mouse models suggest that $\mathrm{AD}$ does not involve only neuronal and synaptic degeneration but rather causes aberrant network activity that interferes with cognitive functions. In addition, AD is associated with an increase in the incidence of epileptic seizures
(García-Cabrero et al., 2013; Palop and Mucke, 2009, 2010; Verret et al., 2012), which may be responsible for alterations of neural network activity. In this regard, some studies point to GABAergic neuron dysfunction as the main factor responsible for network alterations associated with cognitive deficits in AD and aging (Andrews-Zwilling et al., 2010, 2012; McQuail et al., 2015; Palop et al., 2007; Palop and Mucke, 2010). The GABAergic SHP regulates hippocampal rhythmic activity by selective innervation on GABAergic hippocampal interneurons (Buzsaki, 2002; Hangya et al., 2009), which in turn control large number of pyramidal and granular neurons (Freund and Buzsaki, 1996; Freund and Katona, 2007).

We recently found that amyloid- $\beta$ accumulation in J20 mice induces abnormal GABAergic $\mathrm{SH}$ innervation that correlates with altered patterns of neuronal activity in the hippocampus and with internal processes related to operant rewards (Rubio et al., 2012; Vega-Flores et al., 2014). In the present study, we sought to examine whether the second AD-associated pathological hallmark, hyperphosphorylation of Tau protein, is also associated with alterations in the GABAergic SHP innervating hippocampal interneurons. First, we demonstrate an accumulation of AT180-positive P-Tau in pyramidal neurons in the CA1-3 regions, in the mossy cells in the DG, and also in basket and axo-axonic PARVpositive hippocampal interneurons of VLW mice. To the best of our knowledge, this study is the first to describe P-Tau accumulation in PARV-positive interneurons and mossy cells. It has been shown that PARV-positive interneurons display remarkably extensive axonal arborizations, which are believed to synchronize the firing of hundreds of hippocampal pyramidal neurons (Freund and Buzsaki, 1996; Matyas et al., 2004). Interestingly, Thr231P-Tau
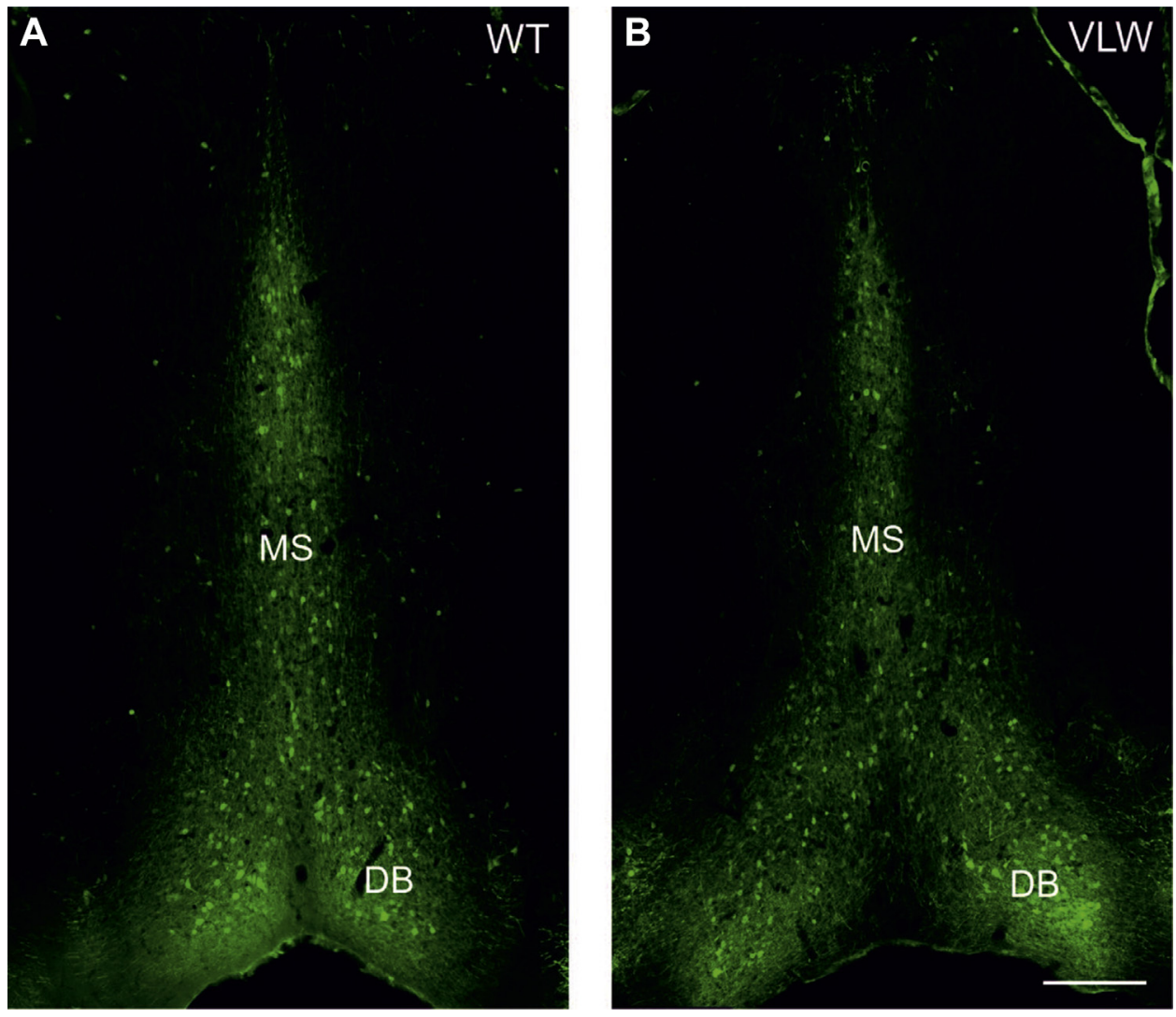

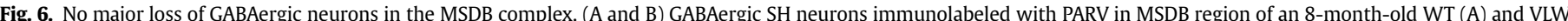

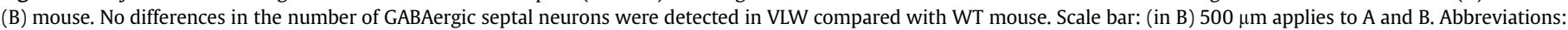
DB, Diagonal Band of Broca; MS, medial septum; PARV, parvalbumin; SH, septohippocampal; WT, wild-type mouse. 
accumulation was restricted to PARV-positive interneurons (with no expression in CALB-, CALR-, or SOM-positive interneurons), thereby suggesting that this process selectively affects the interneurons responsible, to a large extent, for the mechanisms that drive synchronous circuits in the hippocampus (Cardin et al., 2009; Korotkova et al., 2010; Mann and Paulsen, 2005; Sohal et al., 2009). Furthermore, in contrast to hippocampal pyramidal neurons, which present P-Tau recognized by AT-180, AT-8, and 12E8 antibodies, PARV-positive interneurons accumulated P-Tau specifically in Thr231. This observation points to a distinct regulation of Tau phosphorylation in different hippocampal neuronal types, probably linked to differential signaling pathways. The significance of such differential phosphorylation remains to be elucidated.

Hippocampal hyperexcitability can lead to the degeneration of GABAergic septal neurons (Garrido Sanabria et al., 2006). To analyze a possible toxic effect of P-Tau accumulation in PARVimmunoreactive cells on either septal neurons or hippocampal interneurons, we quantified the density of PARV-positive cells in the hippocampus and in the septum (Figs. 3 and 6). Our data indicate no neuronal loss as a direct effect of P-Tau accumulation. Accordingly, the hyperexcitability described in VLW mice (García-Cabrero et al., 2013) does not appear to be a consequence of hippocampal interneuron death.

GABAergic hippocampal neurons are the specific targets of the GABAergic SH connection involved in the establishment of theta and gamma rhythms in the hippocampus (Buzsaki, 2002; Freund and Antal, 1988; Gangadharan et al., 2016; Hangya et al., 2009). In addition, the GABAergic SH connection has an electrophysiological function that is indispensable for spatial learning and memory (Düzel et al., 2010; Fries, 2015; Gangadharan et al., 2016). In this regard, previous studies report cognitive deficiencies caused by septal GABAergic neuron degeneration (Dwyer et al., 2007; Köppen et al., 2013; Pang et al., 2011; Roland et al., 2014). Our previous data indicate a dramatic reduction of GABAergic $\mathrm{SH}$ innervation in a mouse AD model accumulating amyloid- $\beta$ (Rubio et al., 2012). In addition, a decrease in GABAergic SH activity and memory deficits associated with theta rhythms has been reported in response to amyloid- $\beta$ pathology (Rubio et al., 2012; Villette et al., 2010). To determine whether P-Tau accumulation affects the pattern of GABAergic SH innervation, we subjected VLW mice to tracer injections. Our data show a slight reduction in GABAergic SH innervation on GAD65/67-positive neurons and a marked decrease in the complexity of GABAergic SH contacts, specifically on P-Taupositive interneurons. This observation is reinforced by a considerable reduction of GABAergic SH innervation (both percentage of cells and density of innervation) in PARV-positive interneurons, which accumulate P-Tau in their somatodendritic domain. The reduction of GABAergic SH innervation on PARV-positive neurons was detected early in the DG and CA3 of 2-mo VLW mice, thereby suggesting a possible effect of P-Tau accumulation during the development of the GABAergic SH connection in these areas. The alterations were more obvious at 8 months, and the differences between 2- and 8-mo VLW mice were more dramatic than those in WT mice. These observations therefore also indicate early synaptic degeneration of GABAergic SH contacts on PARV-positive neurons in VLW mice.

P-Tau accumulation in neurons affects dendritic spines, synapses, and basic processes such as axonal transport (Ballatore et al., 2007; Frost et al., 2015; Hernández and Avila, 2007; Ittner et al., 2010). It has been reported that basket and axo-axonic interneurons are crucial for rhythmic hippocampal activity and that alterations in these interneurons in humans correlate with hyperexcitability and epilepsy (DeFelipe, 1999; Freund and Katona, 2007). Together, our data indicate a central role of PARV-positive interneurons in P-Tau pathology and suggest that the hyperexcitability and cognitive alterations described in VLW mice are a consequence of a PARV-positive interneuron dysfunction caused by either P-Tau accumulation, the loss of GABAergic SH input on these cells, or a combination of both. Tau mediates amyloid- $\beta$ toxicity in dendrites in AD. Moreover, Tau-reduction ameliorates susceptibility to excitotoxic seizures and cognitive deficits induced by amyloid- $\beta$ (Crimins et al., 2013; Ittner et al., 2010; Roberson et al., 2007). All these results support the notion that Tau makes a critical contribution to the synaptic alterations associated with AD. Accordingly, our present data show impairment in GABAergic SH synapses in a model of tauopathy, similar to the alteration in the same connection associated with amyloid- $\beta$ accumulation in J20 mice. This observation suggests that P-Tau may be the common alteration responsible for GABAergic synaptic impairment, and, as a consequence, of the altered hippocampal rhythmical activity and cognitive deficiencies associated with AD. Additional physiological animal models combining amyloid- $\beta$ accumulation with the phosphorylation of Tau protein, or mice expressing human mutated Tau under Tau endogenous promoter, or histological analysis of samples from AD patients will shed light on the role of Tau protein in GABAergic innervation in $\mathrm{AD}$.

Our data, together with our previous results, demonstrate that both amyloid- $\beta$ and P-Tau accumulation impair GABAergic $\mathrm{SH}$ innervation. We propose that the loss of GABAergic SH input contributes to the altered patterns of synchronous activity and the cognitive deficits associated with early manifestations of AD. In addition, our findings suggest that a PARV-positive interneuron dysfunction, caused by P-Tau accumulation, combined with a decrease in GABAergic SH innervation on these neurons, underlies the cognitive deficits present in tauopathies, including AD.

\section{Disclosure statement}

The authors have no actual or potential conflicts of interest to disclose.

\section{Acknowledgements}

The authors thank the personnel of the Advanced Digital Microscopy Facilities at the Institute for Research in Biomedicine for support. The authors are grateful to D. E. Parruca da Cruz for his participation in some preliminary experiments of this study. This work was supported by funds from the Ministry of Economy and Competitiveness of Spain (SAF2013-42455-R) awarded to E. Soriano.

\section{Appendix A. Supplementary data}

Supplementary data related to this article can be found at http:// dx.doi.org/10.1016/j.neurobiolaging.2016.09.006.

\section{References}

Andrews-Zwilling, Y., Bien-Ly, N., Xu, Q., Li, G., Bernardo, A., Yoon, S.Y., Zwilling, D. Yan, T.X., Chen, L., Huang, Y., 2010. Apolipoprotein E4 causes age- and taudependent impairment of GABAergic interneurons, leading to learning and memory deficits in mice. J. Neurosci. 30, 13707-13717.

Andrews-Zwilling, Y., Gillespie, A.K., Kravitz, A.V., Nelson, A.B., Devidze, N., Lo, I. Yoon, S.Y., Bien-Ly, N., Ring, K., Zwilling, D., Potter, G.B., Rubenstein, J.L.R. Kreitzer, A.C., Huang, Y., 2012. Hilar GABAergic interneuron activity controls spatial learning and memory retrieval. PLoS ONE 7, e40555.

Ballatore, C., Lee, V.M.-Y., Trojanowski, J.Q., 2007. Tau-mediated neurodegeneration in Alzheimer's disease and related disorders. Nat Rev. Neurosci. 8, 663-672.

Bland, B.H., Declerck, S., Jackson, J., Glasgow, S., Oddie, S., 2007. Septohippocampal properties of N-methyl-D-aspartate-induced theta-band oscillation and synchrony. Synapse 61, 185-197. 
Bloom, G.S., 2014. Amyloid- $\beta$ and tau: the trigger and bullet in Alzheimer disease pathogenesis. JAMA Neurol. 71, 505-508.

Buzsaki, G., 2002. Theta oscillations in the hippocampus. Neuron 33, 325-340.

Buzsáki, G., 2005. Theta rhythm of navigation: link between path integration and landmark navigation, episodic and semantic memory. Hippocampus 15, $827-840$.

Cardin, J.A., Carlen, M., Meletis, K., Knoblich, U., Zhang, F., Deisseroth, K., Tsai, L.H., Moore, C.I., 2009. Driving fast-spiking cells induces gamma rhythm and controls sensory responses. Nature 459, 663-667.

Castellani, R.J., Rolston, R.K., Smith, M.A., 2010. Alzheimer disease. Dis. Mon. 56, 484-546.

Crimins, J.L., Pooler, A., Polydoro, M., Luebke, J.I., Spires-Jones, T.L., 2013. The intersection of amyloid beta and tau in glutamatergic synaptic dysfunction and collapse in Alzheimer's disease. Ageing Res. Rev. 12, 757-763.

DeFelipe, J., 1999. Chandelier cells and epilepsy. Brain 122 (Pt 10), 1807-1822.

Düzel, E., Penny, W.D., Burgess, N., 2010. Brain oscillations and memory. Curr. Opin. Neurobiol. 20, 143-149.

Dwyer, T.A., Servatius, R.J., Pang, K.C., 2007. Noncholinergic lesions of the medial septum impair sequential learning of different spatial locations. J. Neurosci. 27, 299-303.

Freund, T.F., 1989. GABAergic septohippocampal neurons contain parvalbumin. Brain research. 478, 375-381.

Freund, T.F., Antal, M., 1988. GABA-containing neurons in the septum control inhibitory interneurons in the hippocampus. Nature 336, 170-173.

Freund, T.F., Buzsaki, G., 1996. Interneurons of the hippocampus. Hippocampus 6, $347-470$.

Freund, T.F., Gulyas, A.I., 1997. Inhibitory control of GABAergic interneurons in the hippocampus. Can. J. Physiol. Pharmacol. 75, 479-487.

Freund, T.F., Katona, I., 2007. Perisomatic inhibition. Neuron 56, 33-42.

Fries, P., 2015. Rhythms for cognition: communication through coherence. Neuron $88,220-235$.

Frost, B., Götz, J., Feany, M.B., 2015. Connecting the dots between tau dysfunction and neurodegeneration. Trends Cell Biol. 25, 46-53.

Gangadharan, G., Shin, J., Kim, S.-W., Kim, A., Paydar, A., Kim, D.-S., Miyazaki, T., Watanabe, M., Yanagawa, Y., Kim, J., Kim, Y.-S., Kim, D., Shin, H.-S., 2016. Medial septal GABAergic projection neurons promote object exploration behavior and type 2 theta rhythm. Proc. Natl. Acad. Sci. U. S. A. 113, 6550-6555.

García-Cabrero, A.M., Guerrero-López, R., Giráldez, B.G., Llorens-Martín, M., Ávila, J., Serratosa, J.M., Sánchez, M.P., 2013. Hyperexcitability and epileptic seizures in a model of frontotemporal dementia. Neurobiol. Dis. 58, 200-208.

Garner, H.L., Whittington, M.A., Henderson, Z., 2005. Induction by kainate of theta frequency rhythmic activity in the rat medial septum-diagonal band complex in vitro. J. Physiol. 564, 83-102.

Garrido Sanabria, E.R., Castaneda, M.T., Banuelos, C., Perez-Cordova, M.G., Hernandez, S., Colom, L.V., 2006. Septal GABAergic neurons are selectively vulnerable to pilocarpine-induced status epilepticus and chronic spontaneous seizures. Neuroscience 142, 871-883.

Goedert, M., Jakes, R., Crowther, R.A., Cohen, P., Vanmechelen, E., Vandermeeren, M., Cras, P., 1994. Epitope mapping of monoclonal antibodies to the paired helical filaments of Alzheimer's disease: identification of phosphorylation sites in tau protein. Biochem. J. 301 (Pt 3), 871-877.

Gulyas, A.I., Gorcs, T.J., Freund, T.F., 1990. Innervation of different peptide-containing neurons in the hippocampus by GABAergic septal afferents. Neuroscience 37, $31-44$.

Gulyas, A.I., Hajos, N., Freund, T.F., 1996. Interneurons containing calretinin are specialized to control other interneurons in the rat hippocampus. J. Neurosci. 16, 3397-3411.

Hangya, B., Borhegyi, Z., Szilagyi, N., Freund, T.F., Varga, V., 2009. GABAergic neurons of the medial septum lead the hippocampal network during theta activity. J. Neurosci. 29, 8094-8102.

Hernández, F., Avila, J., 2007. Tauopathies. Cell Mol. Life. Sci. 64, 2219-2233.

Ittner, L.M., Ke, Y.D., Delerue, F., Bi, M., Gladbach, A., van Eersel, J., Wölfing, H., Chieng, B.C., Christie, M.J., Napier, I.A., Eckert, A., Staufenbiel, M., Hardeman, E., Götz, J., 2010. Dendritic function of tau mediates amyloid-beta toxicity in Alzheimer's disease mouse models. Cell 142, 387-397.

Kitchigina, V., Popova, I., Sinelnikova, V., Malkov, A., Astasheva, E., Shubina, L., Aliev, R., 2013. Disturbances of septohippocampal theta oscillations in the epileptic brain: reasons and consequences. Exp. Neurol. 247, 314-327.

Köppen, J.R. Winter, S.S., Stuebing S.L, Cheatwood, J.L., Wallace, D.G., 2013. Infusion of GAT1-saporin into the medial septum/vertical limb of the diagonal band disrupts self-movement cue processing and spares mnemonic function. Brain Struct. Funct. 218, 1099-1114.

Korotkova, T., Fuchs, E.C., Ponomarenko, A., von Engelhardt, J., Monyer, H., 2010. NMDA receptor ablation on parvalbumin-positive interneurons impairs hippocampal synchrony, spatial representations, and working memory. Neuron 68, 557-569.

Lim, F., Hernández, F., Lucas, J.J., Gómez-Ramos, P., Morán, M.A., Avila, J., 2001. FTDP17 mutations in tau transgenic mice provoke lysosomal abnormalities and Tau filaments in forebrain. Mol. Cell. Neurosci. 18, 702-714.

Loreth, D., Ozmen, L., Revel, F.G., Knoflach, F., Wetzel, P., Frotscher, M., Metzger, F., Kretz, O., 2012. Selective degeneration of septal and hippocampal GABAergic neurons in a mouse model of amyloidosis and tauopathy. Neurobiol. Dis. 47, $1-12$.
Mann, E.O., Paulsen, O., 2005. Mechanisms underlying gamma ('40 Hz') network oscillations in the hippocampus-a mini-review. Prog. Biophys. Mol. Biol. 87, $67-76$.

Matyas, F., Freund, T.F., Gulyas, A.I., 2004. Immunocytochemically defined interneuron populations in the hippocampus of mouse strains used in transgenic technology. Hippocampus 14, 460-481.

McQuail, J.A., Frazier, C.J., Bizon, J.L., 2015. Molecular aspects of age-related cognitive decline: the role of GABA signaling. Trends Mol. Med. 21, 450-460.

Mucke, L., Masliah, E., Yu, G.Q., Mallory, M., Rockenstein, E.M., Tatsuno, G., Hu, K. Kholodenko, D., Johnson-Wood, K., McConlogue, L., 2000. High-level neuronal expression of abeta 1-42 in wild-type human amyloid protein precursor transgenic mice: synaptotoxicity without plaque formation. J. Neurosci. 20, 4050-4058.

Palop, J.J., Chin, J., Roberson, E.D., Wang, J., Thwin, M.T., Bien-Ly, N., Yoo, J., Ho, K.O., Yu, G.Q., Kreitzer, A., Finkbeiner, S., Noebels, J.L., Mucke, L., 2007. Aberrant excitatory neuronal activity and compensatory remodeling of inhibitory hippocampal circuits in mouse models of Alzheimer's disease. Neuron 55, 697-711.

Palop, J.J., Jones, B., Kekonius, L., Chin, J., Yu, G.Q., Raber, J., Masliah, E., Mucke, L. 2003. Neuronal depletion of calcium-dependent proteins in the dentate gyrus is tightly linked to Alzheimer's disease-related cognitive deficits. Proc. Natl. Acad. Sci. U. S. A. 100, 9572-9577.

Palop, J.J., Mucke, L., 2009. Epilepsy and cognitive impairments in Alzheimer disease. Arch. Neurol. 66, 435-440.

Palop, J.J., Mucke, L., 2010. Amyloid-[beta]-induced neuronal dysfunction in Alzheimer's disease: from synapses toward neural networks. Nat. Neurosci. 13 $812-818$

Pang, K.C.H., Jiao, X., Sinha, S., Beck, K.D., Servatius, R.J., 2011. Damage of GABAergic neurons in the medial septum impairs spatial working memory and extinction of active avoidance: effects on proactive interference. Hippocampus 21 $835-846$.

Pascual, M., Perez-Sust, P., Soriano, E., 2004. The GABAergic septohippocampa pathway in control and reeler mice: target specificity and termination onto reelin-expressing interneurons. Mol. Cell. Neurosci. 25, 679-691.

Pascual, M., Pozas, E., Soriano, E., 2005. Role of class 3 semaphorins in the development and maturation of the septohippocampal pathway. Hippocampus 15 184-202.

Paxinos, G., Franklin, K.B.J., 2001. The Mouse Brain in Stereotaxic Coordinates, second ed. Academic Press, San Diego, Calif.

Pike, F.G., Goddard, R.S., Suckling, J.M., Ganter, P., Kasthuri, N., Paulsen, O. 2000. Distinct frequency preferences of different types of rat hippocampal neurones in response to oscillatory input currents. J. Physiol. 529, 205-213.

Roberson, E.D., Scearce-Levie, K., Palop, J.J., Yan, F., Cheng, I.H., Wu, T., Gerstein, H. Yu, G.Q., Mucke, L., 2007. Reducing endogenous tau ameliorates amyloid betainduced deficits in an Alzheimer's disease mouse model. Science 316, $750-754$.

Rocamora, N., Pascual, M., Acsady, L., deLecea, L., Freund, T.F., Soriano, E., 1996. Expression of NGF and NT3 mRNAs in hippocampal interneurons innervated by the GABAergic septohippocampal pathway. J. Neurosci. 16 3991-4004.

Rodríguez-Navarro, J.A., Gómez, A., Rodal, I., Perucho, J., Martinez, A., Furió, V. Ampuero, I., Casarejos, M.J., Solano, R.M., de Yébenes, J.G., Mena, M.A., 2008. Parkin deletion causes cerebral and systemic amyloidosis in human mutated tau over-expressing mice. Hum. Mol. Genet. 17, 3128-3143.

Roland, J.J., Stewart, A.L., Janke, K.L., Gielow, M.R., Kostek, J.A., Savage, L.M., Servatius, R.J., Pang, K.C.H., 2014. Medial septum-diagonal band of Broca (MSDB) GABAergic regulation of hippocampal acetylcholine efflux is dependent on cognitive demands. J. Neurosci. 34, 506-514.

Rubio, S.E., Vega-Flores, G., Martínez, A., Bosch, C., Pérez-Mediavilla, A., del Río, J. Gruart, A., Delgado-García, J.M., Soriano, E., Pascual, M., 2012. Accelerated aging of the GABAergic septohippocampal pathway and decreased hippocampal rhythms in a mouse model of Alzheimer's disease. FASEB J. 26, 4458-4467.

Selkoe, D.J., 1991. The molecular pathology of Alzheimer's disease. Neuron 6, 487-498.

Sohal, V.S., Zhang, F., Yizhar, O., Deisseroth, K., 2009. Parvalbumin neurons and gamma rhythms enhance cortical circuit performance. Nature 459 $698-702$

Sotty, F., Danik, M., Manseau, F., Laplante, F., Quirion, R., Williams, S., 2003. Distinct electrophysiological properties of glutamatergic, cholinergic and GABAergic rat septohippocampal neurons: novel implications for hippocampal rhythmicity J. Physiol. 551, 927-943.

Spires, T.L., Orne, J.D., SantaCruz, K., Pitstick, R., Carlson, G.A., Ashe, K.H. Hyman, B.T., 2006. Region-specific dissociation of neuronal loss and neurofibrillary pathology in a mouse model of tauopathy. Am. J. Pathol. 168, 1598-1607.

Toth, K., Freund, T.F., Miles, R., 1997. Disinhibition of rat hippocampal pyramida cells by GABAergic afferents from the septum. J. Physiol. 500 (Pt 2), 463-474.

Vega-Flores, G., Rubio, S.E., Jurado-Parras, M.T., Gomez-Climent, M.A. Hampe, C.S., Manto, M., Soriano, E., Pascual, M., Gruart, A., DelgadoGarcia, J.M., 2014. The GABAergic septohippocampal pathway is directly 
involved in internal processes related to operant reward learning. Cereb. Cortex 24, 2093-2107.

Verret, L, Mann, E.O. Hang G.B., Barth, A.M.I. Cobos, I., Ho, K. Devidze, N. Masliah, E., Kreitzer, A.C., Mody, I., Mucke, L., Palop, J.J., 2012. Inhibitory interneuron deficit links altered network activity and cognitive dysfunction in Alzheimer model. Cell 149, 708-721.

Villette, V., Poindessous-Jazat, F., Simon, A., Lena, C., Roullot, E., Bellessort, B., Epelbaum, J., Dutar, P., Stephan, A., 2010. Decreased rhythmic GABAergic septal activity and memory-associated theta oscillations after hippocampal amyloidbeta pathology in the rat. J. Neurosci. 30, 10991-11003.

Whitehouse, P.J., Price, D.L., Struble, R.G., Clark, A.W., Coyle, J.T., Delon, M.R., 1982 Alzheimer's disease and senile dementia: loss of neurons in the basal forebrain. Science 215, 1237-1239.

Ypsilanti, A.R., Girao da Cruz, M.T., Burgess, A., Aubert, I., 2008. The length of hippocampal cholinergic fibers is reduced in the aging brain. Neurobiol. Aging 29 1666-1679. 